\title{
Legislation on direct-to-consumer genetic testing in seven European countries
}

\author{
This article has been changed from an Article to Policy since Advance Online Publication
}

\author{
Pascal Borry ${ }^{\star, 1,2}$, Rachel E van Hellemondt ${ }^{3}$, Dominique Sprumont ${ }^{4}$, Camilla Fittipaldi Duarte Jales ${ }^{5}$, \\ Emmanuelle Rial-Sebbag ${ }^{6}$, Tade Matthias Spranger ${ }^{7}$, Liam Curren ${ }^{8}$, Jane Kaye ${ }^{8}$, Herman Nys ${ }^{1}$ and \\ Heidi Howard ${ }^{9}$
}

\begin{abstract}
An increasing number of private companies are now offering direct-to-consumer (DTC) genetic testing services. Although a lot of attention has been devoted to the regulatory framework of DTC genetic testing services in the USA, only limited information about the regulatory framework in Europe is available. We will report on the situation with regard to the national legislation on DTC genetic testing in seven European countries (Belgium, the Netherlands, Switzerland, Portugal, France, Germany, the United Kingdom). The paper will address whether these countries have legislation that specifically address the issue of DTC genetic testing or have relevant laws that is pertinent to the regulatory control of these services in their countries. The findings show that France, Germany, Portugal and Switzerland have specific legislation that defines that genetic tests can only be carried out by a medical doctor after the provision of sufficient information concerning the nature, meaning and consequences of the genetic test and after the consent of the person concerned. In the Netherlands, some DTC genetic tests could fall under legislation that provides the Minister the right to refuse to provide a license to operate if a test is scientifically unsound, not in accordance with the professional medical practice standards or if the expected benefit is not in balance with the (potential) health risks. Belgium and the United Kingdom allow the provision of DTC genetic tests.
\end{abstract}

European Journal of Human Genetics (2012) 20, 715-721; doi:10.1038/ejhg.2011.278; published online 25 January 2012

A wide variety of genetic tests are currently being offered directlyto-consumers by private companies that are located within the USA, Europe and elsewhere. The type of tests being offered to the public are diagnostic tests, (preconceptional) carrier tests, tests indicating a predisposition to common disorders, tests profiling a risk to addiction, nutrigenomic tests, pharmacogenomic tests and ancestry tests. According to the companies selling these tests, individuals have a fundamental right to access information about themselves, including genetic information. ${ }^{1}$ Companies market their tests to consumers on the basis that they will be able to use the test results in their daily life, particularly in monitoring or improving their health conditions. ${ }^{2}$ Moreover, companies maintain that ordering a genetic test outside the traditional healthcare system will result in a better guarantee of privacy, at least with respect to insurance companies and employers. Autonomy, empowerment, prevention, convenience and privacy are usually the keywords in the marketing of these direct-to-consumer (DTC) genetic tests. ${ }^{3}$

There have also been a number of criticisms made about the services that these companies provide to consumers. Although a few companies are currently involving physicians in the provision of their services, ${ }^{4}$ the majority of companies operate without the involvement of a healthcare professional. Indeed, in some cases, a health-care professional may have been hired by the company to 'formally' sign off on orders to circumvent legal issues; ${ }^{5,6}$ most companies do not require consumers to ever interact directly with a health-care professional in order to obtain a genetic test. This is contrary to the way that genetic tests have been provided within most healthcare frameworks. The DTC provision model of genetic tests has been criticized for its absence of individualized medical supervision, ${ }^{7}$ the absence and/or dubious quality of pre- and post-test information provision and genetic counselling, ${ }^{8}$ and the inappropriate genetic testing of minors. ${ }^{9,10}$ This adds to the concerns regarding the limited predictive value, clinical validity and utility of various DTC genetic tests presently on offer. ${ }^{11-13}$ Further concerns include the way that DTC genetic testing companies carry out research, ${ }^{9,14}$ the (lack of) respect for privacy and the potential burden on public health-care resources. ${ }^{15}$

In light of these concerns, various professional organizations and governmental agencies have published statements to inform, educate and/or warn consumers about DTC genetic testing. ${ }^{16-21}$ Along these lines, the European Society of Human Genetics' statement set a bench mark that included recommendations to ensure the quality of the testing services, the provision of pre-test information and genetic counselling, and individualized medical supervision. ${ }^{22}$ Furthermore, most statements have urged for closer regulatory oversight of this

${ }^{1}$ Centre for Biomedical Ethics and Law, Katholieke Universiteit Leuven, Leuven, Belgium; ${ }^{2}$ Department of Clinical Genetics \& Department of Medical Humanities, VU University Medical Center, and EMGO Institute for Health and Care Research, Amsterdam, The Netherlands; ${ }^{3}$ Leiden University Medical Centre, Leiden, The Netherlands; ${ }^{4}$ Institute of Health Law, University of Neuchâtel, Neuchâtel, Switzerland; Institute of Bioethics, Portuguese Catholic University, Porto, Portugal; 6 UMR U 1027, Inserm, Université de Toulouse - Université Paul Sabatier -Toulouse III, Epidémiologie et analyses en santé publique: risques, maladies chroniques et handicap, Département d'épidémiologie et de santé publique, Toulouse, France; ${ }^{7}$ Institute for Public Law, University of Bonn, Bonn, Germany; ${ }^{8}$ HeLEX Centre for Health, Law and Emerging Technologies, University of Oxford, Oxford, UK; 9 Institute for BioMedical Ethics, University of Basel, Basel, Switzerland

${ }^{*}$ Correspondence: Professor P Borry, Centre for Biomedical Ethics and Law, Katholieke Universiteit Leuven, Kapucijnenvoer 35, B0X 7001, Leuven 3000, Belgium. E-mail: Pascal.Borry@med.kuleuven.be 
market. Recently, the US Food and Drug Administration (FDA) has decided to investigate more closely the market activities of DTC genetic testing companies; this may impact on the future regulatory oversight of the DTC genetic testing market both in the US and elsewhere. $^{23,24}$

Although various publications have focused on the regulation of DTC genetic testing activities in the US ${ }^{7,25-31}$ only a limited attention has been devoted to the regulation of these activities in the Europe. ${ }^{32-35}$ Therefore, the aim of this article is to analyze whether specific European countries have national legislation that specifically addresses DTC genetic testing or that have other legislation that may impact on the regulatory control of these genetic testing services. This publication discusses national initiatives from different European countries and does not focus on the European Union legal framework. However, it is important to stress that various European legislations are binding for companies offering DTC genetic testing in the European Union. Specifically, the Directive $95 / 46 /$ EC on the protection of individuals with regard to the processing of personal data and on the free movement of such data; the Directive 2000/31/EC on certain legal aspects of information society services, in particular electronic commerce, in the internal market; the Medical Devices Directives; the Directive 97/7/EC on the protection of consumers in respect of distance contracts; Consumer legislation and the Directive 2006/114/EC concerning misleading and comparative advertising; and the Directive 2005/29/EC concerning unfair business-to-consumer commercial practices and Competition Law.

\section{METHODS}

Experts in Health Law (all co-authors of this paper) from seven European countries (Belgium, Germany, France, the Netherlands, Portugal, Switzerland and the United Kingdom) were contacted by $\mathrm{PB}$ and $\mathrm{HCH}$ to describe the regulatory frameworks that apply to DTC genetic testing activities in their countries. In answering this question, they were asked first, whether their country had legislation that specifically addressed the issue of DTC genetic testing, and second, whether there was legislation that regulated genetic testing services in general. These countries were selected on the basis of the willingness of experts to participate and on the basis of previous involvement in debates on this subject. The United Kingdom has been the most active European country in this area. Since 1997, the Advisory Committee on Genetic Testing ${ }^{36}$ and subsequently the Human Genetics Commission (HGC) has published various documents specifically addressing the issue of DTC genetic testing. ${ }^{18,37,38}$ In Belgium, the National Advisory Committee on Bioethics prepared a document on this issue in $2004^{39}$ and the Superior Health Council is at this moment debating whether more regulatory control for DTC genetic testing is necessary. In France and Portugal, the National Consultative Ethics Committee for Health and Life Sciences ${ }^{40}$ and the National Council for Ethics in the Life Sciences, respectively, issued statements on the direct marketing of genetic tests in 2008. ${ }^{41}$ In the Netherlands, the Health Council ${ }^{42}$ and the Council for Public Health and Health Care ${ }^{43}$ both published a report on self-testing, discussing DTC genetic testing as well. In Switzerland, the Swiss Society of Medical Genetics had published a statement on DTC genetic testing. ${ }^{44}$ In Germany, DTC genetic testing has been discussed in relation to new legislation ${ }^{45}$ and in a report elaborated by German National Academy of Sciences. ${ }^{46}$ This demonstrates that this is a key issue across Europe, and there has been considerable debate around the best way to regulate this area.

\section{RESULTS \\ Belgium}

In Belgium, no specific legislation forbids or regulates the provision of DTC genetic tests. A Royal Decree of 14 December 1987 (published in the Belgian Official Journal of 25 December 1987) lays down the rules for the provision of genetic testing in the Centres for Human Genetics in Belgium. Genetic examinations are only reimbursed by statutory health insurance if they are carried out at one of the eight recognized Centres for Human Genetics. No information is provided about the potential provision of genetic testing outside this context. The only legal basis applying to DTC genetic tests could be found in article 2 of the Law on the practice of health-care professions (Royal decree $\mathrm{n}^{\circ} 78$ (B.S. 14.11.1967)), which stipulates that a physician should be involved in the practice of medicine. Hence, if a DTC genetic test falls under the practice of medicine, as a consequence, a physician should be involved and the law on patient rights would apply. In this respect, it is important to determine whether a DTC genetic test could be considered the 'practice of medicine'. As we know, most DTC companies write in their 'terms of services' that they are not practicing medicine, and that their tests should not be considered medical information, but only serve 'informational purposes'. Whether or not this statement would stand further legal or judicial scrutiny has yet to be proven.

\section{France}

In France, genetic tests are well described and framed in the context of health, and this legislation could apply to the DTC context. According to the French Law (Article 16-1 Civil Code) genetic tests can only be performed for an individual for 'medical or scientific research purposes'. When accomplished in a medical context, the genetic analysis should fulfill one of the following elements: (a) to give, confirm or refute the diagnosis of genetic disease for an individual; (b) to detect characteristics of one or more genes, which may be the cause of developing a disease by a person or family members potentially affected; or (c) to adapt the medical care of a person according to its genetic characteristics (Article R1131-1 Public Health Code). As a consequence, there is no possibility in France to access a genetic test for another aim, for example, just to obtain information. Moreover, the Public Health Code provides some complementary provisions with regard to (a) the quality of laboratories and training of scientists and (b) the respect of the medical relationship. First, in order to perform genetic tests in France, laboratories need to get a specific authorization delivered for 5 years, by the Head of the Regional Agency for Health after consultation of the Biomedicine Agency (Article R1131-14, Public Health Code). In the same way, geneticists must conform to specific requirements to perform genetic tests. They must be specifically trained to be able to verify the results of a genetic analysis (Articles R1131-6 and R1131-7, Public Health Code). Second, the use of genetic tests in the clinical context means that the relationship between the user (patient) and the provider (medical doctor) should be defined as a 'medical relationship'. Any other use outside of this context is outlawed and cannot be covered by the following provisions. The French Law gives details on the respect of various duties regarding the terms of the patients (or their family) information, the test prescription and the announcement of the results (Articles R1131-4 and following). The law is also strict on the requirements for consent, which must be obtained in writing after the patient has been informed of the nature and the purposes of the test. This regulation insists on the importance of the quality of the information delivered by a medical doctor or explained by a genetics counsellor.

During the revision process of the French Bioethics Law (Law 2004800 of 6 August 2004 on Bioethics, JO 182 of 7 August 2004 adapting the Law 94-653 of 29 July 1994 on respect for the human body and the Law 94-654 of 29 July 1994 on the gift and use of parts and products of the human body, for medical assistance to procreation and prenatal diagnosis), some of the preparatory reports underlined the necessity to 
elaborate specific provisions with regard to DTC genetic testing. Considering that DTC tests are being offered internationally and that anticipating the scope of the consumer demand in France will be very difficult, these reports have encouraged the legislator to adopt two kinds of provisions. The conclusions of the reports proposed that, first, prohibition for individuals to use the results of these tests in France should be enshrined in law, and, second, that the Biomedicine Agency should be charged to watch the websites offering these tests to ensure their quality and validity (Parliamentary Office on Scientific and Technological Choices (evaluation of the application of the Law of 6 August 2004 on Bioethics, 20 November 2008), Biomedicine Agency (the evaluation of the Law of 6 August 2004 on Bioethics, 2008), information mission on the revision of the Bioethics Law (Information Report $\mathrm{n}^{\circ} 2235$, deposited on 20 January 2010)).

Finally, the new Bioethics Law that entered into force on 7 July 2011 (Law n ${ }^{\circ}$ 2011-814 of 7 July 2011, published JORF n 01578 July 2011, page 11826) has implemented most of these proposals. The most significant of these is that from the persons' rights perspective, for the first time the French Public Health code prohibits a person from requesting a genetic test for herself or for a third person, or for identification through her DNA profile, outside the conditions laid by the law (Article L.1133-4-1). This action is punishable under the article 226-28-1 of the criminal code by a fine of 3.750 Euro. Second, from the institutional perspective, the French Bioethics Law reinforces the conditions to be fulfilled by the laboratories, which perform genetic tests. In particular, the new article L. 1131-2-1 (Public Health Code) specifies that the study of the genetic characteristics of a person or the identification of a person through his DNA profile can only be performed by authorized and accredited laboratories (which excludes companies that are not considered as laboratories). Finally, the Biomedicine Agency is unlikely to be in charge of website surveillance due to the difficulty of such a management. Nevertheless the new law added a new mission for the Agency to 'make information about the uses of direct to consumer genetic tests available to the public and to elaborate a benchmark for the evaluation of their quality' (Article L. 1418-1 paragraph 9, Public Health Code). The modalities to implement this measure are not given by the law. It will be up to the Biomedicine Agency to act as an independent body and to choose the best way to ensure and fulfill this mission.

\section{Germany}

In Germany, there is no legislation that specifically addresses the issue of DTC genetic testing. However, on 24 April 2009 the German Bundestag passed the Human Genetic Examination Act (The Genetic Diagnosis Act, GenDG) ${ }^{47}$ which covers some aspects of these genetic testing services. A prior aim of this law, which came into effect on the 1 February 2010 (sec. 27 para. 1; for divergences, see sec. 27 para. 2 to 4 ), is on one hand the strengthening of the right to informational self-determination concerning the execution of diagnostic or predictive genetic tests, and on the other hand the protection against abusive use of the information originating from genetic testing and screening. The Act, however, focuses on tests carried out under specific circumstances. As sec. 2 para. 1 points out, the act only applies to genetic examinations and genetic analyses conducted within the framework of genetic examinations involving born natural persons, as well as embryos and fetuses during pregnancy and the handling of genetic data and genetic samples gained thereby for medical purposes, for purposes of determining descent as well as in the insurance and employment sectors. This Act does not apply to genetic analyses or the handling of genetic samples or genetic data conducted for research purposes or on the basis of applicable regulations relating to criminal procedures or the Infection Protection Act.

According to sec. 7 para. 1 of the Act, a diagnostic genetic examination may only be undertaken by physicians and a predictive genetic examination may only be undertaken by medical specialists in the field of human genetics or other physicians who have qualified themselves via the acquisition of some specialist designation for genetic examination within their specialist area. Para. 2 states that the genetic analysis of a biological sample may only be carried out within the scope of a genetic examination and by the medical person in charge or by person or institution commissioned by the responsible medical doctor. Para. 3 finally declares that genetic counselling according to sec. 10 may only be undertaken by physicians named in para. 1 and who are qualified to provide genetic counselling.

Furthermore, a precondition for valid informed consent is the clarification presented in sec. 9 para. 1-3: 'Before obtaining consent, the medical person in charge must inform the person concerned on the nature, meaning and consequences of the genetic examination. After being informed the person concerned must receive sufficient time for consideration before deciding to provide consent. The clarification covers in particular: (1) the purpose, type, scope and significance of the genetic examination including the results attainable in the course of the purpose of the examination and with the designated means of examination; the foregoing also includes any genetic characteristics which are to be examined and which are significant in terms of avoiding, preventing or treating any illness or health condition; (2) the health risks for the person concerned which are connected to the knowledge of the results of the genetic examination and the procurement of the necessary biological sample (...); (3) the intended use of any sample as well as the results of any genetic examination or analysis; (4) the right of the person concerned to revoke his or her consent at any time; (5) the right of the concerned person to not have to know results (...)'.

Under this legislation, the DTC provision of genetic tests in Germany is clearly restricted. Genetic tests can only be carried out by a medical doctor after the provision of sufficient information concerning the nature, meaning and consequences of the genetic test, and after the consent of the person concerned. The German Law described in this article does not regulate tests for research purposes, but companies cannot just avoid this legislation by suggesting that their tests are for research and educational purposes only. However, the mere sale of test kits and the application of DTC GT outside the areas described are not prohibited per se, and individuals purchasing tests from abroad will not be penalized. Finally, it must also be noted that the legal discussion of the DTC problem has just begun and therefore many questions are still open. In particular, the relevance of self-determination as a legal concept and the degree to which German Law requires protection of the person concerned from their own decisions remains to be clarified.

\section{The Netherlands}

The Netherlands has no legislation that specifically addresses DTC genetic testing. ${ }^{48}$ In principle, companies are allowed to offer DTC genetic tests to the public. However, the Dutch Act on population screening (henceforth Act), ${ }^{49}$ by way of a permit system, seeks to protect individuals against screening programmes that may be a threat to health. This legal framework was introduced to establish and guarantee a fair balance between the right of self-determination of 
individuals and the need to protect them against (potentially) harmful screening programmes. ${ }^{50}$ Hence, although the Act on population screening was not developed to regulate the access and the use of DTC genetic tests specifically, it does apply to certain of these tests.

In this Act, population screening is defined as 'a medical examination which is carried out in response to an offer made to the entire population or to a section thereof and to detect diseases of a certain kind or certain risk indicators, either wholly or partly for the benefit of the persons examined. ${ }^{49}$ The key word in the definition is 'offer'. DTC genetic tests that predict diseases on the basis of risk indicators fit within this definition due to the fact that companies advertise and offer their genetic tests directly to the public in magazines, newspapers and through the Internet. The fact that individuals visit the website or the web shop of 'test companies' on their own initiative makes no difference when classifying DTC genetic tests as population screening.

According to the Act, some forms of DTC genetic tests can only be carried out with a permit issued by the Dutch Minister of Welfare and Sports. Offering and practicing DTC genetic tests for detecting (risk factors of) cancer and (risk factors of) 'incurable' diseases which can neither be treated nor prevented - without a licence is against the law in the Netherlands. Moreover, performing these tests without permission is a punishable offence (Article 3 (1) and Article 13). ${ }^{49}$ Based on article 7 , the responsible Dutch Minister can refuse to provide a licence if a test is scientifically unsound, is not in accordance with the professional medical practice standards or if the expected benefit is not in balance with the (potential) health risks. The Act does not set up quality norms for the information to be provided to consumers of DTC genetic tests nor for consent to use samples and counselling to be provided. Nevertheless, DTC genetic testing companies wishing to sell genetic tests for detecting (risk factors of) cancer and (risk factors of) 'incurable' diseases have to comply with the professional medical practice standards, which entail the main rights of patients laid down in the Dutch Civil Code.

Furthermore, the Dutch 'Medical Treatment Contracts Act', as part of the Dutch Civil Code, applies to all contracts whereby a health-care provider undertakes to provide medical services. The main purpose of this 'Act' is to clarify and strengthen the legal position of the patient. It lays down the rights and obligations of care providers and the patient. Among other rights, it sets up quality norms for the information to be provided, for obtaining consent and how to deal with confidential patient data. According to the 'Medical Treatment Contracts Act', health-care providers have to give information about the indication, the proposed treatment, alternatives, prognoses, risks and possible side effects before starting with a medical intervention.

The Dutch permit system guarantees normative criteria for DTC genetic tests aimed at detecting (risk indicators of) cancer and (risk indicators of) 'incurable' diseases. This legal framework effectively prevents individuals from getting access to some DTC genetic tests, with a questionable validity and clinical utility in the Netherlands.

However, from the beginning there was confusion about the scope of the Act, and thus uncertainty about the requirement of obtaining a licence. The Health Council - a scientific advisory body - has been allotted the task of advising the Minister on the provision of a licence to applicants under the Act (Article 6). The Dutch Health Council has written several reports to clarify the scope of the Act. Despite these helpful reports certain uncertainties remain that are probably inherent to the use of terms like 'population screening', 'offer' and incurable'. In the light of these difficulties, already more than 10 years ago there was a call to revise the Act in order to enhance its effectiveness. ${ }^{50}$

\section{Portugal}

In Portugal, the Law $\mathrm{n}^{\circ} 12 / 2005$ of 26 January $2005^{51}$ defines the concept of health information and genetic information, and sets forth rules for the collection and preservation of biological products for genetic testing for clinical or research purposes. In article 10 of this law, different genetic tests are categorized based on use: tests to be used for the detection of carriers of recessive disorders; pre-symptomatic tests for monogenic diseases; predictive tests allowing the detection of susceptibility genes; pharmacogenetic tests; prenatal tests and tests used for screening. According to article 9.2 of the Law $n^{\circ} 12 / 2005$, the detection of the heterozygosity status of recessive diseases, the presymptomatic diagnosis of monogenic diseases and the tests for genetic susceptibility in healthy persons can only be carried out by request of a medical geneticist, following a genetic counselling consultation and subject to the express written and informed consent of the person in question. Article 9.7 also advances that in situations of risk of severe, late-onset diseases that appear in the beginning of adulthood and that have no cure or proven effective treatment, the performance of any presymptomatic or predictive testing must be preceded by a previous psychological and social evaluation and by the follow-up of the patient after the delivery of the tests results. Besides, article 17.3 also states that every citizen has the right to receive genetic counselling and, if appropriate, psychological and social support, before and after heterozygosity, presymptomatic, predictive or prenatal genetic tests. In this context, it is also important to state that Portugal ratified the Oviedo Convention, ${ }^{52}$ through Presidential Decree $n^{\circ} 01 / 2001$, which means that the aforementioned Convention has force of law throughout the national territory. According to article 12 of this convention, 'tests which are predictive of genetic diseases or which serve either to identify the subject as a carrier of a gene responsible for a disease or to detect a genetic predisposition or susceptibility to a disease may be performed only for health purposes or for scientific research linked to health purposes and subject to appropriate genetic counselling. ${ }^{52}$ Finally, in July 2008, the National Council of Ethics for the Life Sciences ${ }^{41}$ issued an opinion that genetic testing for health purposes should not be offered directly to the public, in compliance with fundamental ethical principles. This document is not a legally binding document.

Based on these provisions, various jurists advance that DTC genetic testing is forbidden in Portugal. ${ }^{53}$ However, article 15 of Law $n^{\circ} 12 / 2005$ still attributes responsibility to the Government to regulate the conditions of availability and performance of genetic testing. This is meant to prevent that tests are made available by national or foreign laboratories that do not have the support of a proper and multidisciplinary medical team, and to avoid the possible over-the counter marketing of this type of tests. Notwithstanding this legal provision and an Order, issued in September 2008, by the Ministry of Health, ${ }^{54}$ creating a work force to regulate the Law $\mathrm{n}^{\circ} 12 / 2005$, there are still no regulations that determine measures for accreditation, certification and licensing of public and private laboratories responsible for genetic testing. As a consequence, there is no specific legislation addressing DTC genetic testing enacted yet, and according to some authors, no real legal provisions prohibiting DTC genetic testing services.

\section{Switzerland}

In Switzerland, the conditions under which human genetic testing may be performed has been regulated under the Federal Act on Human Genetic Testing ${ }^{55}$ from 8 October 2004. ${ }^{56}$ The genetics tests offered directly-to-consumers correspond to the definition of 'genetic in vitro diagnostic medical devices' as formulated by article $3 \mathrm{j}$ of the above mentioned law: 'ready-to-use products for the determination of 
characteristics of human genetic material'. Those tests are covered by Article 9 of this Act that reads as follow: '(1) It is forbidden to supply genetic in vitro diagnostic medical devices to individuals for a purpose which cannot be considered part of those individuals' professional or commercial activities; (2) The Federal Council may, having consulted the Expert Commission for Human Genetic Testing, make provision for exceptions to this prohibition provided the products are used under medical supervision and misinterpretation of the test result is not possible'.

The Act has been completed by two ordinances: the Federal Council Ordinance on Human Genetic Testing from 14 February $2007^{57}$ and the Federal Department of Home Affairs Ordinance on Human Genetic Testing from 14 February 2007. ${ }^{58}$ None of these regulations provide for an exception to article 9 of the Act prohibition for DTC genetic testing. To the best of our knowledge, no one has yet requested from the competent authorities the right to benefit from the exceptions mentioned in the Act. One could therefore conclude that such tests remain unlawful in Switzerland.

In fact, the $\mathrm{Act}^{55}$ makes it a criminal penalty to infringe this prohibition as stated in article 38: '(1) Any person who, in contravention of Article 9 paragraph 1, wilfully supplies genetic in vitro diagnostic medical devices to individuals for a purpose which cannot be considered part of those individuals' professional or commercial activities shall be liable to a fine; (2) If the act is committed for commercial gain, the penalty shall be a custodial sentence not exceeding three years or a monetary penalty'.

Yet, it should be underlined that the prohibition or at least the severe restriction of the law is limited to putting those devices on the market, and not the use of them. There is no explicit sanction in the law against someone who imported such test for his or her personal use. The issue is indeed very similar to the one importing any therapeutic products. In practice, this is tolerated by the law as long as it remains limited to personal use and does not present a risk in terms of public health. For genetic testing, there is still another dimension as there are many companies advertising on the Internet that offer simple and rather inexpensive paternity tests. ${ }^{59}$ The key point in this case is that the test requires testing not only the potential father(s) but also the child. When the latter is a minor, there is a clear conflict of interest for the 'father' to consent for him or her, especially when he is not actually the legal father. Courts have already decided that such tests are invalid and could not be used to challenge the family links between a man and a child. There could also be an issue of liability as the test could be considered as an infringement of the personal rights of each person whose DNA is analyzed without their consent ${ }^{60}$ - without mentioning his or her legal parents if their family relationship is denied - and therefore open the way for obtaining indemnities.

\section{United Kingdom}

Within the UK, there is no specific legislation that relates to genetic testing in general and nothing that addresses DTC in particular. However, if a DTC genetic testing company operated in, and from, the UK, it would have to comply with a wide range of legislation and other regulatory factors. There are a number of statute-based Laws that a UK-based DTC company should be aware of, all of which are at least partly anchored in the realm of consumer protection. These legal instruments - variously acts (or 'primary legislation' made by the UK Parliament) and regulations (or 'secondary legislation' typically made by a senior minister authorized by primary legislation) - for the most part reflect a wider, harmonized European position (i.e. on medical devices, general consumer protection, advertisements, contractual terms or data protection). While these laws are not unique to the UK, there are provisions in the UK Human Tissue Act 2004 legislation primarily concerned with the use of biological samples rather than data - that criminalize genetic analysis of human tissue without the consent of the donor. Obtaining the valid consent of genetic test consumers in the UK is therefore extremely important.

The common law system in the UK provides another layer of law, through which judge-made decisions can either serve to clarify the application of existing legislation or 'fill in the gaps' where there are no appropriate acts or regulations. There have, as yet, been no court or tribunal decisions concerning matters pertinent to DTC genetic tests, meaning that the most relevant aspect of the common law will be the general obligations of confidentiality applicable to the test results provided to consumers. Such obligations will, of course, overlap with many of the responsibilities created by Data Protection Law.

The most relevant, and recent, regulatory instrument that applies to DTC genetic tests in the UK comes in the form of a voluntary set of guidelines drawn up by the UK HGC: an advisory, rather than a regulatory body. The 2010 'Common Framework of Principles' aims to 'promote high standards and consistency' in the provision of DTC genetic tests by commercial providers, so as to 'safeguard the interests' of consumers and their families. ${ }^{18}$ The HGC Principles cover matters such as information to be provided to prospective consumers, counselling and continuing support, the role of consent, laboratory processes, the provision and interpretation of results, and complaints procedures. It will be interesting to see how many companies - based in the UK and elsewhere - make a point of demonstrating compliance with the HGC Principles, particularly as the HGC is soon to be disbanded as part of the UK Government's current cost-cutting drive. Finally, other regulatory schemes that DTC genetic test companies should be aware of include voluntary accreditation schemes for testing undertaken in laboratories (for example, those offered by the United Kingdom Accreditation Service), codes of practice relevant to certain types of advertising and general consumer-facing business practices. (Dealt with the Advertising Standard Authority and The Office of Fair Trading, respectively).

\section{DISCUSSION}

This report provides an overview of national legislation in seven EU countries with regard to DTC genetic testing services. All countries discussed have national legislation that partly or fully applies to DTC genetic testing. However, none have legislation that was created specifically to regulate DTC genetic testing services and therefore it was necessary to use analogy or interpretation of existing legislation. A common pattern was that the legislation in many of the countries stipulated that genetic tests should be offered only under medical supervision and with genetic counselling. This is the case in France, Germany, the Netherlands, Portugal and Switzerland. In these countries, the underlying premise is that individuals should be given the opportunity to make their decisions freely and this should be based on adequate information about the limitations of (DTC) genetic tests and their (physical, psychological and social) implications.

This position is in line with the latest developments within Europe regarding the regulatory control of genetic testing, which is found in the 2008 Additional Protocol to the 1997 Convention for the Protection of Human Rights and Dignity of the Human Being with regard to the application of Biology and Medicine, concerning Genetic Testing for Health Purposes. ${ }^{61}$ This Additional Protocol (although not currently binding) is the first European legal instrument in this area 
and has been opened for signing since November 2008. The original European Convention on Human Rights and Biomedicine states in Article 12 that 'tests which are predictive of genetic diseases or which serve either to identify the subject as a carrier of a gene responsible for a disease or to detect a genetic predisposition or susceptibility to a disease may be performed only for health purposes or for scientific research linked to health purposes, and subject to appropriate genetic counselling. The 2008 Additional Protocol on genetic testing stated in article $7 \S 1$ that 'a genetic test for health purposes may only be performed under individualised medical supervision' ${ }^{61}$

In the Explanatory Memorandum to the Protocol, which is important for the interpretation of the Protocol, it is explained that article 7 $\S 1$ has been 'driven by the concern to enable the person concerned to have suitable preliminary information with a view to an informed decision regarding the carrying out of this test and, if appropriate, to have access to appropriate genetic counselling. A precise evaluation of the situation of the person concerned, involving direct contact with him of her, is a determining element in that respect. A mere telephone conversation with a medical doctor, for example, does not allow for such evaluation'. ${ }^{62}$ In addition, the protocol states that genetic tests should meet well-accepted criteria of scientific validity and clinical validity (article 5), and that clinical utility of genetic tests should be an essential criterion for deciding to offer a test to a group of persons (article 6). Moreover, it underlines that individuals should be provided with prior appropriate information and appropriate genetic counselling (article 8). This legislation mirrors the recommendation that was expressed by some professional organizations. For example, the American Medical Association advanced in a letter to the American Food and Drug Administration that 'genetic testing, except under the most limited circumstances, should be carried out under the personal supervision of a qualified health-care professional, and provide individuals interested in obtaining genetic testing access to qualified health-care professionals for further information.'.63 Although the Committee of Ministers of the Council of Europe approved the additional protocol, this document has until now only been signed in Finland, France, Iceland, Luxembourg, Moldavia and Slovenia. The two last countries have also ratified it in their internal legislation.

It is also evident that there will need to be further debate to define the type of services (and information) offered by DTC genetic testing companies, and whether or not this is relevant in legal terms. There have been attempts to clearly distinguish 'medical genetic tests' (which are to be ordered by a healthcare provider and which are used to make a treatment decision or diagnosis) and 'informational genetic tests' (which could be ordered directly by an individual and which aim to gain a better understanding of general health and disease susceptibility). ${ }^{64}$ Most DTC genetic testing companies are adamant that the genetic information they provide to consumers is 'not intended to substitute for professional medical advice, diagnosis or treatment' and that this information is only for informational purposes. ${ }^{3,34}$ Almost every company provides disclaimers on their website and consent forms with the aim to inform consumers of the limitations of the tests that they are providing as well as to give themselves some protection from liability. In countries such as France, the Netherlands, Portugal and Switzerland such a distinction doesn't seem to influence the application of the relevant regulation, but in Belgium and Germany such a distinction has a role in the interpretation whether or not a DTC genetic test would be covered by the law.

The Netherlands have a quite unique permit system that guarantees normative criteria for DTC genetic tests aimed at detecting risk indicators of cancer and of 'incurable' diseases. This legal framework aims to prevent individuals from getting access to DTC genetic tests with a questionable validity and clinical utility in the Netherlands. The problem with these different regulatory approaches is enforcement. National enforcement measures can easily by bypassed because DTC tests are offered through the Internet. Without an international regulatory framework, the enforcement of whether or not a company is adhering to several national or regional legislations is based on voluntary compliance by the company. We observed that some DTC genetic testing companies respect the fact that DTC genetic testing is outlawed in certain American States, and state on their website that they do not process samples submitted from citizens from these states.

The protection of individuals against questionable testing services calls for international vigilance and comprehensive measures by the international community. As international regulatory oversight is difficult to achieve, considerable effort has put into working with the DTC industry in order to develop a code of practice. ${ }^{18}$ It has also been suggested that an international product quality certificate (such as an International Standards Organisation (ISO)) should be introduced that controls for compliance with ethical standards, provisions for counselling and stringent standards of scientific validity ${ }^{65}$ Effort is also being put into improving the functioning of in vitro diagnostics medical devices regulations. ${ }^{66,67}$

\section{CONCLUSION}

In this paper, we have focussed on national initiatives from European countries rather than on the European Union Framework itself. We have demonstrated that there are differences in approaches as well as similarities between countries within Europe. However, as Europe is a sui generis multilevel system of governance, Europe's regulatory framework is required to respond not only to processes of economic and political integration but also seek to harmonize rules at a transnational level regarding health and consumers protection. Therefore, in the challenge is whether it is possible to provide uniform normative guidance for DTC genetic testing across all European States, when there are different national legal systems and different methods have been used to regulate DTC.

\section{ACKNOWLEDGEMENTS}

$\mathrm{HCH}$ is funded by the European Commission FP7 Marie Curie initiative. REV is funded by the Centre for Society and Genomics in the framework of the Netherlands Genomics Initiative. JK is funded by the Welcome Trust WT081407/Z/06/Z; LC is funded by the European Commission FP7 project BIOSHARE; ERS is supported by the TEGALSI contract Institut de recherche en santé publique (Services de santé-politiques publiques et santé 2009).

1 Ledley F: A consumer charter for genomic services. Nat Biotechnol 2002; 20: 767

2 Foster MW, Royal CDM, Sharp RR: The routinisation of genomics and genetics: implications for ethical practices. J Med Ethics 2006; 32: 635-638.

3 Howard HC, Borry P: Personal genome testing: do you know what you are buying? Am J Bioethics 2009; 9: 11-13.

4 Howard HC, Borry P: Is there a doctor in the house? The presence of physicians in the direct-to-consumer genetic testing context. J Community Genet 2011 (in press).

5 Mitchell PB, Meiser B, Wilde A et al: Predictive and diagnostic genetic testing in psychiatry. Clin Lab Med 2010; 30: 829-846.

6 Wadman M: Gene-testing firms face legal battle. Nature 2008; 453: 1148-1149.

7 Hogarth S, Javitt G, Melzer D: The current landscape for direct-to-consumer genetic testing: legal, ethical, and policy issues. Annu Rev Genomics Hum Genet 2008; 9: 161-182.

8 Wade $\mathrm{CH}$, Wilfond BS: Ethical and clinical practice considerations for genetic counselors related to direct-to-consumer marketing of genetic tests. Am J Med Genet C Semin Med Genet 2006; 142: 284-292.

9 Borry P, Howard HC, Senecal K et al: Direct-to-consumer genome scanning services. Also for children? Nat Rev Genet 2009; 10: 8. 
10 Borry P, Howard HC, Senecal K et al: Health-related direct-to-consumer genetic testing: a review of companies' policies with regard to genetic testing in minors. Fam Cancer 2009; 9 (1): 51-59.

11 Janssens AC, Gwinn M, Bradley LA et al: A critical appraisal of the scientific basis of commercial genomic profiles used to assess health risks and personalize health interventions. Am J Hum Genet 2008; 82: 593-599.

12 Mihaescu R, van HM, Sijbrands EJ et al: Evaluation of risk prediction updates from commercial genome-wide scans. Genet Med 2009; 11: 588-594.

13 Foster MW, Mulvihill JJ, Sharp RR: Evaluating the utility of personal genomic information. Genet Med 2009; 11: 570-574.

14 Howard HC, Knoppers BM, Borry P: Blurring lines. The research activities of direct-toconsumer genetic testing companies raise questions about consumers as research subjects. EMBO Rep 2010; 11: 579-582.

15 McGuire A, Diaz CM, Wang T et al: Social networkers' attitudes toward direct-toconsumer personal genome testing. Am J Bioethics 2009; 9: 3-10.

16 American College of Obstetricians and Gynaecologists ACOG Committee Opinion No 409: Direct-to-consumer marketing of genetic testing. Obstet Gynecol 2008; 111: 1493-1494.

17 Federal Trade Commission: FTC Facts for Consumers. At-Home Genetic Tests: a Healthy Dose of Skepticism may be the Best Prescription 2009, http://www.ftc.gov/ bcp/edu/pubs/consumer/health/hea02.shtm (accessed 26 April 2011).

18 Human Genetics Commission: A Common Framework of Principles for Direct-toConsumer Genetic Testing Services 2010, http://www.hgc.gov.uk/Client/ document.asp?Docld=280\&CAtegoryld=10 (accessed 2 May 2011).

19 United States Government Accountability Office: Nutrigenetic Testing: Tests Purchased from four Websites Mislead Consumers. Washington: US GAO, 2006.

20 United States Government Accountability Office: Direct-to-Consumer Genetic Tests Misleading Test Results are Further Complicated by Deceptive Marketing and Other Questionable Practices 2010, http://democrats.energycommerce.house.gov/ documents/20100722/Kutz.Testimony.07.22.2010.pdf (accessed 17 January 2011).

21 Nuffield Council on Bioethics: Medical Profiling and Online Medicine: the Ethics of 'Personalised Healthcare' in a Consumer Age. Oxfordshire: Nuffield Press, 2010.

22 European Society of Human Genetics Statement of the ESHG on direct-toconsumer genetic testing for health-related purposes. Eur J Hum Genet 2010; 18: 1271-1273.

23 Allison M: Genetic testing clamp down. Nat Biotechnol 2010; 28: 633.

24 Genetics and Public Policy Center, 2008, http://www.dnapolicy.org/resources/ DTCcompanieslist.pdf.

25 Tamir S: Direct-to-consumer genetic testing: ethical-legal perspective and practical considerations. Med Law Rev 2010; 18: 213

26 Solberg LB: Over the counter but under the radar: direct-to-consumer genetics tests and FDA regulation of medical devices. Vand J Ent \&Tech L 2009; 11 711-1141.

27 Gniady JA: Regulating direct-to-consumer genetic testing: protecting the consumer without quashing a medical revolution. Fordham L Rev 2007; 76: 2429.

28 Novy MC: Privacy at a price: direct-to-consumer genetic testing \& the need for regulation. U III JL Tech \& Pol'y 2010; 2010: 157-239.

29 Bernstein G: Direct-to-Consumer Genetic Testing: Gatekeeping the Production of Genetic Information. University of Missouri at Kansas City Law Review 2010; 79: 283-295

30 Wagner JK: Understanding FDA regulation of DTC genetic tests within the context of administrative law. Am J Hum Genet 2010; 87: 451-456.

31 Robertson AS: Taking responsibility: regulations and protections in direct-to-consumer genetic testing. Berkeley Tech LJ 2009; 24: 213.

32 van Hellemondt RE, Hendriks AC, Breuning $\mathrm{MH}$ : Regulating the use of genetic tests: is Dutch law an example for other countries with regard to DTC genetic testing? Amsterdam Law Forum 2011; 3: 13-24.

33 Bonneau D, Marlin S, Sanlaville D et al: Genetic testing in the context of the revision of the French law on bioethics. Pathol Biol (Paris) 2010; 58: 396-401.

34 Kaye J: The regulation of direct-to-consumer genetic tests. Hum Mol Genet 2008; 17 : R180-R183.

35 Borry P: Europe to ban direct-to-consumer genetic tests? Nat Biotechnol 2008; 26 736-737.

36 Advisory Committee on Genetic Testing: Code of Practice and Guidance on Human Genetic Testing Services Supplied Direct to the Public. London: Health Departments of the United Kingdom, 1997.

37 Human Genetics Commission: Genes direct. Ensuring the Effective Oversight of Genetic Tests Supplied Directly to the Public 2003, http://www.hgc.gov.uk.

38 Human Genetics Commission: More Genes Direct. A Report on Developments in the Availability, Marketing and Regulation of Genetic Tests Supplied Directly to the Public 2007, http://www.hgc.gov.uk.

39 Belgian Advisory Committee on Bioethics: Opinion no. 32 of 5 July 2004 on the free availability of genetic tests, 2004, http://www.health.fgov. be/bioeth.

40 National Consultative Ethics Committee for Health and Life Sciences: Opinion no. 86. Problems connected to marketing self-kits for HIV screening and diagnosis of genetic disease, 2004, http://www.ccne-ethique.fr.
41 National Council for Ethics in the Life Sciences: Opinion no. 56 on direct marketing of genetic tests to the public 2008, http://www.cnecv.pt/admin/files/data/docs/ 1273504469 56CNECV2008 EN.pdf.

42 Health Council of the Netherlands: Report on Screening for Disease 2007. The SelfTesting of Body Samples. The Hague: Health Council of the Netherlands, 2007.

43 Raad voor de volksgezondheid: Zelftests. Zoutermeer: RVG, 1999.

44 Swiss Society of Medical Genetics Tests génétiques sur Internet: Bulletin Des Medecins Suisses 2011; 2009: 9

45 Katz G, Schweitzer SO: Implications of Genetic Testing for Health Policy. Yale J Health Pol'y L \& Ethics 2010; 10: 90-197.

46 German National Academy of Sciences: Predictive Genetic Diagnostics as an Instrument of Disease Prevention. Halle: German National Academy of Sciences, 2010.

47 Bundesrat Gesetz über genetische Untersuchungen bei Menschen (Gendiagnostikgesetz-GenDG) [Human Genetic Examination Act (The Genetic Diagnostis Act)] 2009, http://www.gfhev.de/de/startseite_news/2009_GenDG_mit_freundl_genehmg_Baz_ Verlag.pdf (accessed 19 April 2011).

48 van Hellemondt RE, Hendriks AC, Breuning $\mathrm{MH}$ : Regulating the use of genetic tests: is Dutch law an example for other countries with regard to DTC genetic testing? Amsterdam Law Forum 2011; 3: 13-24

49 Wet op het bevolkingsonderzoek [Dutch Act on Population Screening] 1992 http://wetten.overheid.nl/BWBR0005699/geldigheidsdatum 09-02-2010 (accessed 19 April 2011).

50 Van der Maas PJ, Gevers JKM, Roscam Abbing HDC: Evaluatie Wet op het Bevolkingsonderzoek. Den Haag: Zorg Onderzoek Nederland, 2000.

51 Lei $n^{\circ}$ 12/2005. Informação genética pessoal e informação de saúde [Personal genetic information and health information law] 2005 http://dre.pt/pdf1sdip/2005/01/ 018A00/06060611.pdf (accessed 19 April 2011).

52 Council of Europe: Convention for the Protection of Human Rights and Dignity of the Human Being with Regard to the Application of Biology and Medicine: Convention on Human Rights and Biomedicine. Oviedo: Council of Europe, 1997.

53 Sequeiros J: Personal Communication, e-mail 3 March 20112011.

54 Direcção-Geral da Saúde: Despacho N 22784/2008 2011, http://dre.pt/pdf2sdip/ 2008/09/172000000/3874338743.pdf (accessed 19 April 2011)

55 Federal Assembly of the Swiss Confederation: Federal Act on Human Genetic Testing 810.12 2004, http://www.admin.ch/ch/e/rs/8/810.12.en.pdf (accessed 19 April 2011).

56 Sprumont D: Quelle réglementation des trousses d'analyse génétique; In: Joye C (ed): L'analyse génétique humaine: quelles perspectives legislatives. Geneva: Schulthess, 2004; 71-88.

57 Federal Assembly of the Swiss Confederation: Federal Council Ordinance on Human Genetic Testing. 810.122.1 2007, http://www.admin.ch/ch/f/rs/8/810.122.1.fr.pdf (accessed 19 April 2011).

58 Federal Department of Home Affairs: Ordinance on Human Genetic Testing 810.122.122 2007, http://www.admin.ch/ch/f/rs/8/810.122.122.fr.pdf (accessed 19 April 2011).

59 Sprumont D, Quéloz N, Benoît A et al: Conditions de liciéité des tests de paternité par I'analyse d'ADN en dehors du cadre judiciaire. Pratique Juridique Actuelle 2003; 11: $1280-1290$

60 Büchler A: Aussergerichtliche Abstammungsuntersuchungen - Die neuen Bestimmungen des Bundesgesetzes über die genetischen Untersuchungen beim Menschen (GUMG). ZVW 2005; 32-44.

61 Council of Europe: Additional Protocol to the Convention on Human Rights and Biomedicine, concerning Genetic Testing for Health Purposes 2008, http:// conventions.coe.int/treaty/en/treaties/html/203.htm (accessed 17 January 2012).

62 Council of Europe: Explanatory Report to the Additional Protocol to the Convention on Human Rights and Biomedicine, concerning Genetic Testing for Health Purposes 2008, http://conventions.coe.int/Treaty/EN/Reports/Html/203.htm (accessed 17 January 2012).

63 American Medical Association: AMA letter to the FDA regarding molecular and clinical genetics panel of medical devices advisory committee 2011, http://www.ama-assn. org/ama1/pub/upload/mm/399/consumer-genetic-testing-letter.pdf (accessed 27 April 2011).

64 Personalized Medicine Coalition: An Introduction to Informational Genetic Testing 2008, http://www.personalizedmedicinecoalition.org/sites/all/themes/zen_pmc/documents/ Medco-PMC-consumer-genetics.pdf (accessed 17 January 2012).

65 Hauskeller C: Direct to consumer genetic testing. BMJ 2011; 342: d2317.

66 Eurogentest: Official Response of the EuroGentest Network of Excellence in Genetic Testing to the Public Consultation on the Revision of Directive 98/79/ec of the European Parliament and of the Council of 27 October 1998 on in vitro Diagnostic Medical Devices 2010, https://www.eshg.org/fileadmin/www.eshg.org/documents/received/EuroGentestResponseToIVDDRevisionConsultation.pdf (accessed 2 March 2011).

67 European Society of Human Genetics: Official Response of the European Society of Human Genetics to the Public Consultation on the Revision of Directive 98/79/ec of the European Parliament and of the Council of 27 October 1998 on in vitro Diagnostic Medical Devices 2010, https://www.eshg.org/fileadmin/www.eshg.org/documents/ ESHG/ESHG-IVD-def.pdf (accessed 2 March 2011). 